\title{
ONREL
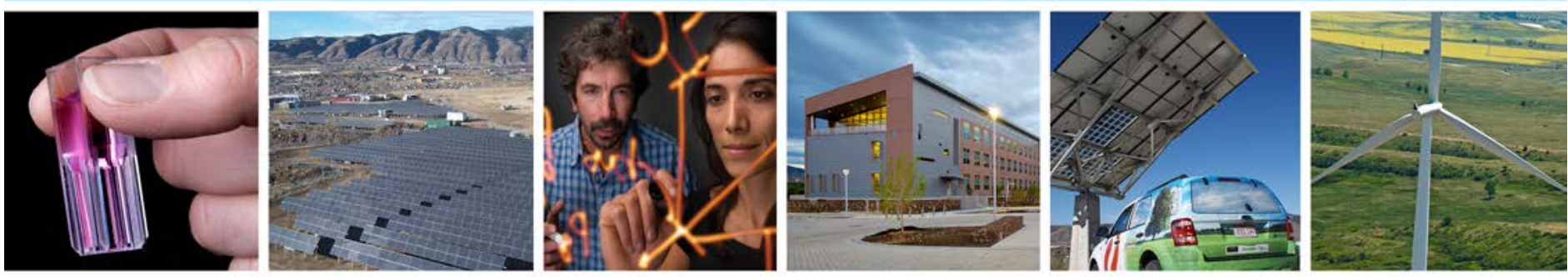

\section{Potential Next Steps for the New Orleans City Council Energy Efficiency Resolution}

Elizabeth Doris

NREL is a national laboratory of the U.S. Department of Energy, Office of Energy Efficiency \& Renewable Energy, operated by the Alliance for Sustainable Energy, LLC. Technical Report

NREL/TP-7A30-52622

September 2011 


\title{
Potential Next Steps for the New Orleans City Council Energy Efficiency Resolution
}

\author{
Elizabeth Doris
}

Prepared under Task No. IDNO.1030

NREL is a national laboratory of the U.S. Department of Energy, Office of Energy Efficiency \& Renewable Energy, operated by the Alliance for Sustainable Energy, LLC.

National Renewable Energy Laboratory 1617 Cole Boulevard Golden, Colorado 80401

303-275-3000 • www.nrel.gov
Technical Report

NREL/TP-7A30-52622

September 2011

Contract No. DE-AC36-08GO28308 


\section{NOTICE}

This report was prepared as an account of work sponsored by an agency of the United States government. Neither the United States government nor any agency thereof, nor any of their employees, makes any warranty, express or implied, or assumes any legal liability or responsibility for the accuracy, completeness, or usefulness of any information, apparatus, product, or process disclosed, or represents that its use would not infringe privately owned rights. Reference herein to any specific commercial product, process, or service by trade name, trademark, manufacturer, or otherwise does not necessarily constitute or imply its endorsement, recommendation, or favoring by the United States government or any agency thereof. The views and opinions of authors expressed herein do not necessarily state or reflect those of the United States government or any agency thereof.

Available electronically at http://www.osti.gov/bridge

Available for a processing fee to U.S. Department of Energy

and its contractors, in paper, from:

U.S. Department of Energy

Office of Scientific and Technical Information

P.O. Box 62

Oak Ridge, TN 37831-0062

phone: 865.576 .8401

fax: 865.576 .5728

email: mailto:reports@adonis.osti.gov

Available for sale to the public, in paper, from:

U.S. Department of Commerce

National Technical Information Service

5285 Port Royal Road

Springfield, VA 22161

phone: 800.553 .6847

fax: 703.605.6900

email: orders@ntis.fedworld.gov

online ordering: http://www.ntis.gov/help/ordermethods.aspx

Cover Photos: (left to right) PIX 16416, PIX 17423, PIX 16560, PIX 17613, PIX 17436, PIX 17721

Printed on paper containing at least $50 \%$ wastepaper, including $10 \%$ post consumer waste 


\section{Acknowledgements}

This work is made possible by the support and guidance of the U.S. Department of Energy Office of Energy Efficiency and Renewable Energy. Project direction and strategy was provided by Steve Chalk and Johanna Zetterberg in that office. The request itself came from the City Council of New Orleans, and the author thanks the input of Shelley Midura, the then Chair of the Utility Committee. The author also appreciates the input and guidance of Phil Voss and Marguerite Kelly at the National Renewable Energy Laboratory (NREL). Finally, thanks to Devin Egan in NREL's Communications Office who provided the technical editing and publications service. 


\section{Document Background}

This document is adapted from an actual February 2008 memo and report by the National Renewable Energy Laboratory (NREL) to the City Council of New Orleans, the office of the Mayor of New Orleans, the Chairperson of the Citizen Stakeholders Group (New Orleans Energy Advisory Committee) and the U.S. Department of Energy (DOE) Project Officer.

\section{Summary}

In January 2008, the New Orleans Utility Committee requested review, commentary, and suggestions for Utility Committee next steps related to the Energy Efficiency Resolution (the Resolution) passed by the City Council in December 2007. ${ }^{1}$ The suggestions are reprinted here as:

1) An illustration of opportunities for other local governments for the development and implementation of effective energy efficiency ordinances and resolutions

2) An example of the type of policy technical assistance that DOE/NREL provides to communities. For more information on the strategy for delivering assistance, please see: www.nrel.gov/docs/fy11osti/48689.pdf.

Based on experience in other communities and energy efficiency policies and programs, NREL found the Resolution to be a solid framework for increasing the responsible use of energy efficiency and reaping the associated economic and environmental benefits in the city of New Orleans.

The remainder of this document provides the requested suggestions for next steps in implementing the word and spirit of the resolution. These suggestions integrate the extensive work of other entities, including the New Orleans Mayor's office, the New Orleans Energy Advisory Committee, the Energy Efficiency Initiative, and the U.S. Environmental Protection Agency's National Action Plan for Energy Efficiency. ${ }^{2}$

In general, three actions were suggested for funding mechanisms, two for near-term successes, and two for longer-term success.

\section{Funding}

- Further review the political and financial viability of a ratepayer charge to fund the energy efficiency programs. An analysis within the report illustrates that the residential monthly fee of $\$ 1.00$ provides a $\$ 1$ million annual fund. This is the most stable and long term of the funding mechanisms reviewed - a value to the resolution. This step includes requesting that Entergy New Orleans provide the cost of making

\footnotetext{
${ }^{1}$ http://www.naco.org/programs/csd/Green\%20Government\%20Database/New\%20Orleans\%20LA\%20Ene rgy\%20Efficiency\%20Resolution.pdf.

${ }^{2}$ www.epa.gov/cleanenergy/energy-programs/suca/resources.html.
} 
necessary changes to the billing and collection system to determine if it is cost prohibitive to establishing such a mechanism.

- Establish a stakeholder committee to identify philanthropic opportunities and ways of pursuing them. The alignment of the philanthropic organization's goals with the city's goals is critical, as is ensuring long term stability of the funding source.

- Identify additional funding mechanisms and the potential to produce stable funding associated with programmatic results.

\section{Program Selection and Implementation - Near Term}

- Data Collection. Take advantage of vast knowledge and interest of stakeholders to create a committee to identify (a) needs, and (b) a comprehensive list of currently available energy and demographic data to form the basis for selecting a list of accepted data sources.

- Evaluate Programmatic Options. Identify and mandate the appropriate cost effectiveness test for programs to create a uniform mechanism for measurement of proposed programs. One commonly used test is a Total Resource Cost test, and there are extensive handbooks on how to implement it and experts could be brought in to discuss options with the City Council.

In the longer term, and in coordination with a comprehensive planning process, NREL suggested pursuing the following larger-scale efforts with the associated next steps.

- Integrated Resource Planning (IRP). If the Utility Committee pursues IRP, the next step is to mandate the process.

- Aligning Utility Incentives with Energy Efficiency Objectives. Because of the relative newness of these policies, and the need to highly customize each, NREL suggests that an expert on each policy be brought in to describe and facilitate the process. 


\section{Acronyms and Abbreviations}

$\begin{array}{ll}\text { DOE } & \text { U.S. Department of Energy } \\ \text { IRP } & \text { Integrated Resource Planning } \\ \text { kWh } & \text { kilowatt hour } \\ \text { MWh } & \text { megawatt hour } \\ \text { NREL } & \text { National Renewable Energy Laboratory } \\ \text { TRC } & \text { total resource cost }\end{array}$




\section{Table of Contents}

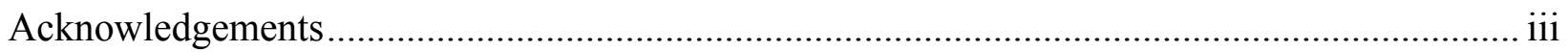

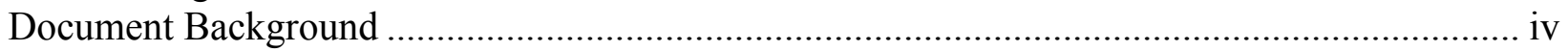

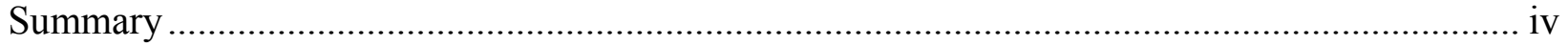

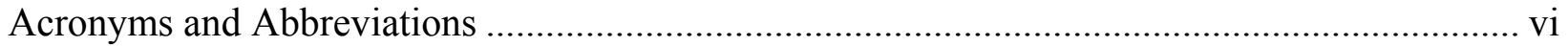

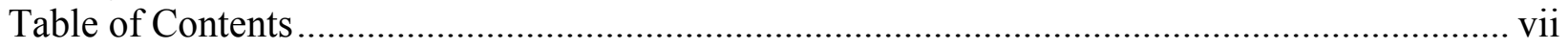

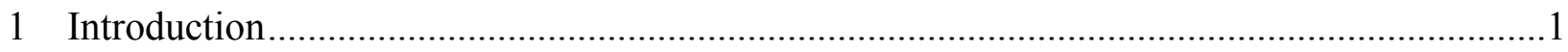

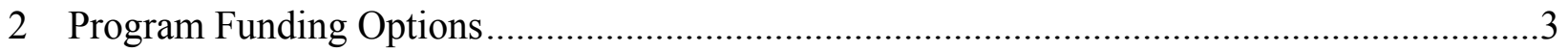

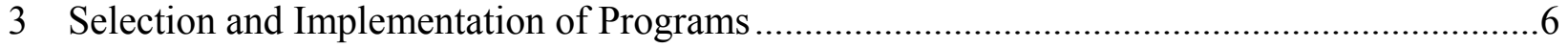

3.1 Development of an Energy Use Baseline for New Orleans........................................6

3.2 Identification of the Potential for Energy Efficiency (Including Conservation) in

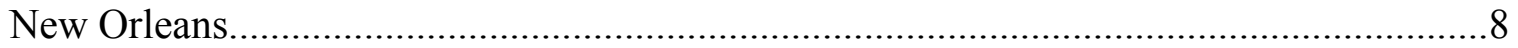

3.3 Develop an Integrated Resource Plan ...............................................................

3.4 Decoupling of Utility Profits from Energy Sales......................................................10

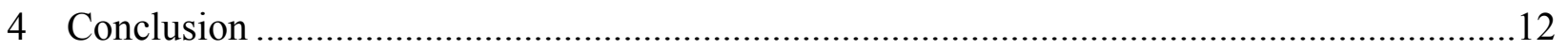




\section{Introduction}

In January 2008, the Utility Committee of the City Council of New Orleans requested that the National Renewable Energy Laboratory (NREL) review and comment on the energy efficiency resolution passed in December 2007. The goal of this review was to determine near-term implementation opportunities related to each resolution.

To complete this review, NREL used knowledge of both the New Orleans specific situation and of other cities that have worked in the direction of optimal energy use. Many stakeholders in New Orleans, including the Mayor's office, the City Council Utility Committee, Entergy New Orleans, and the Energy Policy Advisory Committee, have developed suggestions for next steps, and to the extent possible, those are noted and incorporated. When identifying other cities experiences as examples, a special effort was made to identify cities in similar climatic regions to New Orleans for comparison; exceptional programs and experiences with other applicable aspects for New Orleans are also included.

This report begins with a discussion of programmatic funding, which is critical to the implementation of any of the resolution's many pieces. A number of funding mechanisms are reviewed, including a line item in the city budget, philanthropic and other private funding, and utility and ratepayer funding. One piece of the resolution (\#14) reflects the importance of stable and continuous funding. Because of the uncertainty of many funding mechanisms, an analysis of a ratepayer-funded energy efficiency fund was completed, finding that a $\$ 1$ average monthly increase on residential bills would lead to a consistently funded $\$ 1$ million annual energy efficiency programmatic fund. The potential annual energy use reduction benefit to the whole ratepayer base of approximately 53,000 megawatt hours (MWh) $\left(10^{3}\right.$ kilowatt hours, $\left.\mathrm{kWh}\right)$, is a result of an increase in rate of $\$ 0.00146 / \mathrm{kWh}$. While recognizing that there are capital costs associated with changing the billing system and designing programs, this mechanism is by far the most long-term and stable, within the City Council's purview, of any reviewed.

Next, specific programs that meet the pieces of the resolution are identified. Many of the programs that fit into the energy efficiency resolution grow out of the suggestions of interested stakeholders; those suggestions are reflected in this document. NREL experience shows that programs unified under a common energy goal and mission, such as the result of a comprehensive planning process, have a better chance of maximizing the use of limited resources for implementation. Because of the wealth of programmatic suggestions, as well as the benefits of a comprehensive plan, our review builds on and further develops already proposed suggestions and assumes that a unified goal and mission are established across stakeholders in New Orleans.

From the 16 overlapping resolutions within the Resolution, seven distinct, but interrelated, overarching issues are discussed in this report. The first two are funding related, identifying possible funding mechanisms, challenges, and opportunities. The two funding mechanism options identified are: 
1. Development of a stable funding mechanism for programs, including a program evaluation mechanism (Resolution 14)

2. Identify state-of-the-art billing options for Entergy New Orleans to promote energy efficiency and evaluate cost effectiveness of such options (Resolution 11).

The final four options surround the selection and implementation of actual programs and activities to promote energy efficiency. These are discussed in more detail-defining what they are, how they fit into the resolution, and other energy efficiency-related activities and proposed programs, and next steps for implementation. The first two options are near-term that the utility committee can implement concurrently with the development of a comprehensive energy planning process. The final two are likely outcomes of that process and require longer-term planning to implement, but may have larger impacts over time. These options are discussed in rough order of possible actions:

1. Development of an energy use baseline for New Orleans (Resolution 2)

2. Identification of the potential for energy efficiency (including conservation) in New Orleans with a focus on opportunities within the City Council purview and a costeffectiveness criteria for programs and actions (Resolutions 2, 3, 5, 6, 7, 8, 9, and 16)

3. Development of an integrated resource plan (IRP) (Resolutions 4 and 13)

4. Decoupling of utility profits from energy sales (Resolutions 10 and 16). 


\section{Program Funding Options}

Long-term, stable funding is critical to the development of effective long-term energy savings programs. There are a number of program funding opportunities, but none are guaranteed, permanent, full funding mechanisms. In reality, program funding will need to be combined from a number of resources, thereby marginally increasing the administration costs. Program funding in New Orleans can take many forms and include some or all of the following options. ${ }^{3}$

Funded directly out of city budget. Given the current priorities of rebuilding in New Orleans, it is not expected that energy efficiency programs will be entirely funded through city budgets. In addition, the city budget is fluid, and sustained programs require consistent and continuous funding. Partial funding for staffers and coordination of efforts is a typical contribution from the city budget in energy planning.

Utility funded. Austin Energy, in Texas, and other municipal energy system providers, offer energy efficiency program funding through a portion of profits from energy sales. The benefit to the utility is that reduced energy sales will lead to reduced high-cost peak power purchasing as well as long-term reductions in base load capacity building. Austin Energy estimates that the investment of approximately \$25 million per year since 1982 has resulted in an energy efficiency supply resource equivalent to the annual output of a 500 megawatt (MW) electricity plant. While the comprehensive program at Austin Energy is a leader in energy efficiency programs and has made the city of Austin a leader in optimizing energy use, the municipal nature of the utility has had a significant role in creating the success. Because Entergy New Orleans is an investor-owned utility, the expectation that energy efficiency programs will be fully funded by the utility is unrealistic. However, in the interest of stakeholders, the utility has historically contributed funding to energy efficiency and renewable energy programs. Quantification of the benefits from energy efficiency programs in terms of the impacts on base and peak load power purchasing could assist in estimating the level of utility interest in investment in these programs.

Philanthropic funding. There are a number of philanthropic activities in New Orleans focused on rebuilding and optimizing energy use. Funding for energy efficiency programs may be possible, upon further research, through grant programs and other mechanisms.

Private investment. There are a number of opportunities for private firms to enter the market and promote energy efficiency services (e.g. energy audits and improved energy use at the household or commercial level), and recover their costs through energy savings on the consumer bill. This is similar to an energy savings performance contract mechanism, where an organization amortizes the capital cost over time to the consumer (residential or commercial), thereby transferring the upfront cost of the materials. The

\footnotetext{
${ }^{3}$ Note that not all funding mechanisms are listed here, only a selection of the most commonly used. Bond floating and other mechanisms are currently under review in other cities, but have not been extensively used to this point.
} 
organization contracts to the consumer to pay back the initial costs using the energy savings resulting from the improved energy use. This type of program funding has been successful at the larger scale and may be applicable to the smaller scale.

Ratepayer-supported funding. Many cities and states argue that the benefits of energy efficiency programs, including lower energy bills, reduced pollution, reduced peak power purchasing costs, etc., apply to all ratepayers. That is the basis for the inclusion of a public benefits find (also called systems benefit charge). This is a per-kilowatt-hour charge applied to all customer usage. The money collected is then used to fund a variety of energy efficiency programs as decided by the implementing agency. In some jurisdictions that fund is implemented through the utilities, the regulating body, or a third party designated by the regulating body (such as the Western Electricity Coordinating Council, the New York State Energy Research and Development Authority, or the California Energy Commission).

Stakeholders in New Orleans have expressed concerns that a ratepayer-funded mechanism would put undue financial stress on utility customers. The data in Table 1 represents the impact on ratepayers for different levels of a public benefits fund. The highlighted row shows that a ratepayer fee of $\$ 0.00146 / \mathrm{kWh}$ would result in an increase in average monthly charges of $\$ 1.00$ per customer and a programmatic fund of approximately $\$ 1$ million annually. To translate that to energy use, research shows that 5 $\mathrm{kWh}$ are reduced per dollar of programmatic investment. ${ }^{4}$ At a $\$ 1.00$ per month average residential customer addition, that leads to an annual 53,000 MWh savings. Further resources on public benefits funds can be found at the Clean Energy States Alliance, ${ }^{5}$ a non-profit dedicated to tracking the progress of public benefits funds and their associated programs.

\footnotetext{
${ }^{4}$ SWEEP 2005.

${ }^{5}$ www.cleanenergystates.org/.
} 


\begin{tabular}{|l|l|c|c|c|c|}
\hline \multicolumn{7}{|c|}{ Table 1. Residential Ratepayer Increase Under Various Public Benefit Fund Scenarios in New } \\
Orleans
\end{tabular}

\section{Next Steps for the Utility Committee to pursue funding for energy efficiency programs:}

- Given the purview of the Utility Committee, it is suggested that the most stable of funding mechanisms suggested here be reviewed for political and financial viability. This includes requesting the identification and quantification of capital costs for adding the line item to the Entergy New Orleans billing system for New Orleans customers to finance a public benefits fund.

- Establish a stakeholder committee to identify philanthropic opportunities and ways of pursuing them.

- Identify additional funding mechanisms and the potential to produce stable funding associated with programmatic results. 


\section{Selection and Implementation of Programs}

The remainder of this report provides potential next steps for implementing the resolution. The first two nearer term options the Utility Committee can implement concurrently with the development of a comprehensive energy planning process. The final two are likely outcomes of that process and require longer term planning to implement, but may have larger impacts over time. For each of the four options, the following questions are posed and answered:

Where does this option fit within the Resolution? The Resolution provides high-level guidelines as well as direct programmatic suggestions. As a result, there are some areas of overlap providing for fewer immediate implementation suggestions than the 16 individual resolutions. In this section we relate the program suggestion directly to the areas of the Resolution.

Where does it fit in relation to other suggestions posed to the city? Both City Council requests and voluntarily developed programs have been presented to the Utility Committee. As energy policy planning gains momentum, NREL felt this was an appropriate time to marry these stakeholder suggestions into a unified plan. In this section, we attempt to bring the common threads of these suggestions in line with the City Council Resolution by illustrating commonalities. Note that this is not meant to be a comprehensive listing of alternative proposals, but mainly a summary of programs suggested to the Utility Committee at public meetings. The primary presentations included are the October 2007 Energy Policy Advisory Committee Energy Hawk Report, the September 2007 Energy Efficiency Initiative presented by Henry Consulting, the December 2007 Entergy New Orleans Education Program, and the January 2008 Green Pricing Program. ${ }^{6}$

What is this option? This section defines the option and gives a brief overview and background on the option.

What are the next steps for the Utility Committee to pursue the option? This section highlights the specific potential next steps for the Utility Committee. As policy planning comes more into focus, there is acknowledgement that different stakeholders will take different actions to develop programs. In this section, we attempt to parse out specific next steps for the Utility Committee as requested. As a result of the evolution of energy policy planning in the city and the narrowing of immediate actions, many of these suggestions look toward actual program development and detailed analysis of specific program options, costs, and impacts.

\subsection{Development of an Energy Use Baseline for New Orleans}

\section{Where does this option fit within the Resolution? \#2 BE IT FURTHER RESOLVED} that a process be created to explore the energy efficiency potential in the City and commit

\footnotetext{
${ }^{6}$ These documents were all presented to the City Council of New Orleans in Utility Committee meetings on the dates listed. The presentations are not published on the City Council website.
} 
to its full development by the Utility Committee of the Council of the City of New Orleans.

What is this option? Many of the pieces of the Resolution surround the development of cost-effective programs to pursue energy efficiency opportunities. While national data sources are available (e.g. the U.S. Department of Energy Residential and Commercial Energy Consumption Survey), none of these resources alone are detailed enough to meet the needs of city-level energy program impact evaluation. Without an understanding of energy use across the city, there is no ability to estimate the relative impacts of various programs.

Where does it fit in relation to other suggestions posed to the city? Entergy New Orleans produces an overview report of energy use in their service territory by sector, and the Energy Policy Advisory Committee developed a spreadsheet of energy use by sector derived from the Entergy New Orleans public annual reports

\section{What are the next steps for the Utility Committee to pursue the option?}

Establish a list of accepted data sources for program impact evaluation. So that all programs that are presented can be evaluated on a level playing field, the Utility Committee could identify acceptable and reputable data sources for energy use and demographic information. It is possible that some data sources will need to be developed, but this initial effort will identify what exists and what is needed to implement priority programs (such as consumer and utility incentives, specifically mentioned in the Resolution). It is possible that there is interest from selected stakeholders to form a committee to identify these needs.

\section{Specific Options for Next Steps:}

- Take advantage of vast knowledge of stakeholders and identify (a) needs, and (b) a comprehensive list of currently available energy and demographic data to form a basis for selecting a list of accepted data sources.

This could be a session within a stakeholder energy planning process. For example, to evaluate the impact of a potential residential energy efficiency program, the following is a sample list of questions that would need to be answered:

○ How many existing homes are in New Orleans?

○ How many houses are currently permitted for construction?

○ How many houses are undergoing major renovations?

$\circ$ What is the average size of a home?

$\circ$ What is the average age of a home?

○ What is the average energy use per residential square foot?

○ What appliances are used? 
- Within the Utility Committee purview, more detailed outputs could be required from Entergy New Orleans. With the removal of customer specific data, New Orleansspecific residential, commercial, and industrial energy use and costs can be reported. Detailed information on the breakdown of energy use and cost by rate would offer more detail than the annual report

- Lead by Example: Work with city agencies to develop a baseline for municipal buildings. Measurement of energy use and payments by city agencies and buildings allows for identification of low hanging municipal fruit that can lead to broader public and private adoption of advanced technologies and behaviors.

\subsection{Identification of the Potential for Energy Efficiency (Including Conservation) in New Orleans}

\section{Where does this option fit within the Resolution?}

- \#2 BE IT FURTHER RESOLVED that a process be created to explore the energy efficiency potential in the City and commit to its full development by the Utility Committee of the Council of the City of New Orleans

- \#3 BE IT FURTHER RESOLVED that the Council, through the Utility Committee, identify cost-effective energy efficiency potential in conjunction with its ratemaking authority and responsibility

- \#5 BE IT FURTHER RESOLVED that the Council, through the Utility Committee, establish cost effectiveness tests

- \#6 BE IT FURTHER RESOLVED that the Council, through the Utility Committee, set energy savings goals consistent with the cost-effective potential

- \#7 BE IT FURTHER RESOLVED that the Council, through the Utility Committee, establish appropriate evaluation, measurement, and verification mechanisms

- \#8 BE IT FURTHER RESOLVED that the Council, through the Utility Committee, establish effective energy efficiency delivery mechanisms designed to maximize the use of cost-effective demand-side measures by residents and businesses in New Orleans

- \#9 BE IT FURTHER RESOLVED that the Council, through the Utility Committee, align customer pricing and incentives to encourage investment in energy efficiency

- \#16 BE IT FURTHER RESOLVED that the Council of the City of New Orleans supports the National Action Plan for Energy Efficiency ${ }^{7}$ and the Vision for 2025.

Where does it fit in relation to other suggestions posed to the city? This suggestion allows for the uniform implementation of programs based on a broad stakeholder agreement on the test for cost effectiveness. It will make the evaluation of integrated resource planning, suggested in the Energy Policy Advisory Committee Energy Hawk Report, possible.

\footnotetext{
${ }^{7}$ www.epa.gov/cleanenergy/energy-programs/suca/resources.html.
} 
What is this option? There are a number of established and accepted tests for programmatic cost effectiveness. The total resource cost (TRC) test is commonly used in markets where energy efficiency is actively being planned into the long-term energy plan and IRP. The TRC maximizes welfare by incorporating utility and ratepayer net costs of a program.

Next Steps for Utility Committee to pursue option. Identify and mandate the appropriate cost-effectiveness program test to create a uniform mechanism for measurement. Economic experts with a specialty in prioritization of efficiency as a resource need to be called to advise on different tests.

\subsection{Develop an Integrated Resource Plan}

\section{Where does this option fit within the Resolution?}

- \#4 BE IT FURTHER RESOLVED that the Council, through the Utility Committee, develop processes to align incentives equally for efficiency and supply resources

- \#13 BE IT FURTHER RESOLVED that the Council, through the Utility Committee, shall integrate energy efficiency into energy resource plans at the utility and regulatory level.

Where does it fit in relation to other suggestions posed to the city? The Energy Policy Advisory Committee Energy Hawk Report specifically recommends the development of an IRP.

What is this option? The following summary and definitions for IRP are taken directly from Tellus Institute's Best Practices Guide: Integrated Resource Planning for Electricity: ${ }^{8}$

"Integrated Resource Planning, or IRP, can be thought of as a process of planning to meet users needs for electricity services in a way that satisfies multiple objectives for resource use. Broad objectives can include:

- Conform to national, regional, and local development objectives

- Ensure that all households and businesses have access to electricity services

- Maintain reliability of supply

- Minimize the short term or long term economic cost of delivering electricity services or their equivalent

- Minimize the environmental impacts of electricity supply and use

- Enhance energy security by minimizing the use of external resources

- Provide local economic benefits

- Minimize foreign exchange costs.

\footnotetext{
${ }^{8}$ www.goodcents.com/Info/Best\%20Practices\%20Guide_IRP\%20Planning.pdf.
} 
"Each country, or other planning region, establishes its own objectives to guide planning for electricity services. Objectives such as those listed above are often among those selected to guide IRP. Such objectives as the above conflict with one another to varying degrees. Therefore, preparing, deciding upon, and implementing a preferred resource plan requires both a series of objective analyses and the use of processes by which the values and judgments of stakeholders are applied in developing plans.

"Integrated resource planning is built on principles of comprehensive and holistic analysis. Traditional methods of electric resource planning focused on supply-side projects only, i.e., construction of generation, transmission, and distribution facilities. Demand-side options, which can increase the productivity with which electricity is used by consumers, were not considered. Too often, even the assessment of supply-side options was limited to a few major technologies, and cost-benefit analysis of the alternatives was rudimentary. By contrast, IRP considers a full range of feasible supply-side and demand-side options and assesses them against a common set of planning objectives and criteria.

"IRP, as we intend the approach, is also a transparent and participatory planning process. It contrasts with traditional planning that is typically top-down, with public consultation occurring only as a last step, when plans are virtually complete. IRP can make planning more open to relevant governmental agencies, consumer groups, and others, thus considering the needs and ideas of all parties with a stake in the future of the electric system.

"In summary, IRP provides an opportunity for electric system planners to address complex issues in a structured, inclusive, and transparent manner. At the same time, it provides a chance for interested parties both inside and outside the planning region to review, understand, and provide input to planning decisions."

Next Steps for Utility Committee to Pursue Option: As the utility regulator, the Utility Committee can mandate an IRP process that meets the vision and goals of the larger-scale stakeholder energy planning process.

\subsection{Decoupling of Utility Profits from Energy Sales}

\section{Where does this option fit within the resolution?}

- \#10 BE IT FURTHER RESOLVED that the Council, through the Utility Committee, modify policies to align utility incentives with the delivery of cost-effective energy efficiency and modify, as appropriate, Council ratemaking practices to promote energy efficiency investments

- \#16 BE IT FURTHER RESOLVED that the Council of the City of New Orleans supports the National Action Plan for Energy Efficiency and the Vision for 2025.

Where does it fit in relation to other suggestions posed to the city? The Energy Policy Advisory Committee Energy Hawk Report's recommendation 4.1 is "Create incentives for utility to invest in energy conservation and efficiency." Decoupling the utility profits 
from energy sales is an option for accomplishing that. Chapter 2 of the National Action Plan for Energy Efficiency is a useful resource for information on this suggestion.

What is this option? Decoupling is a form of separating the revenue of a utility from the volumetric sales of energy. There are several forms of decoupling, including one that uses rate cases to determine expected and allowable utility revenue and then trues-up the two at the end of a given amount of time (monthly, annually, etc). There is a great deal of emerging interest and literature on decoupling, and initial qualitative evaluations show that the policies encourage utility participation in energy efficiency programs. Currently, however, there is relatively limited quantitative information on the impacts and successes of the programs because of the relatively recent entrance into the market.

Next Steps for Utility Committee to pursue option. If the Utility Committee decides to pursue this option, NREL suggests that experts on the policy be brought in to assist in identifying the costs and benefits, and to assist on the design and development of the program. There are a number of experts in this area, including the Regulatory Assistance Project ${ }^{9}$ in Vermont. A first step could be requesting a presentation to the Utility Committee on the overall subject of decoupling.

\footnotetext{
${ }^{9}$ www.raponline.org/.
} 


\section{Conclusion}

Overall, there are many options for moving forward to implement the Resolution as presented. The primary next steps for the city are to identify and prioritize the funding options for a long-term program supporting the job development and cost savings benefits to energy efficiency. While there are a number of options, in this paper a public benefit fund type system is reviewed and the impacts on the ratepayers is found to be minimal.

In addition to a stable funding source, other suggested actions include the City Council working with local universities and other stakeholders to develop an energy baseline to measure future impacts of programs, mandating an integrated resource planning process working with the utility, considering decoupling options and supporting the upgrade of the utility billing system. While some of these options include upfront costs, the long term impacts of rebuilding with energy efficiency is within the word and spirit of the existing resolution and could lead to more and higher quality jobs and consistent energy savings for the community. 